\title{
Chain-Length-Dependent Termination in Radical Polymerization of Acrylates
}

\author{
Johannes Barth, Michael Buback, Gregory T. Russell, ${ }^{*}$ Sebastian Smolne
}

M. Buback, J. Barth, S. Smolne

Institute for Physical Chemistry, University of Göttingen, Tammannstraße 6, D-37077

Göttingen, Germany

Fax: +49 551 393144; E-mail: mbuback@gwdg.de

G. T. Russell

Department of Chemistry, University of Canterbury, Private Bag 4800, Christchurch, New Zealand

Fax: +64 3 3642110; E-mail: greg.russell@canterbury.ac.nz

Keywords: acrylates, ESR / EPR, kinetics (polym.), radical polymerization, termination

SUMMARY: The technique of SP PLP EPR, which is single-pulse pulsed-laser polymerization (SP PLP) in conjunction with electron paramagnetic resonance (EPR) spectroscopy, is used to carry out a detailed investigation of secondary (chain-end) radical termination of acrylates. Measurements are performed on methyl acrylate, $n$-butyl acrylate and dodecyl acrylate in bulk and in toluene solution at $-40{ }^{\circ} \mathrm{C}$. The reason for the low temperature is to avoid formation of mid-chain radicals, a complicating factor that has imparted ambiguity to the results of previous studies of this nature. Consistent with these previous studies, composite-model behavior for chain-length-dependent termination rate coefficients, $k_{\mathrm{t}}^{i, i}$, is found in this work. However, lower and more reasonable values of $\alpha_{\mathrm{s}}$, the exponent for variation of $k_{\mathrm{t}}^{i, i}$ at short chain lengths, are found in the present study. Most likely this is because of the absence of mid-chain radicals, thereby validating the methodology of this work. Family-type termination behavior is observed, with the following average 
parameter values adequately describing all results, regardless of acrylate or the presence of toluene: $\alpha_{\mathrm{s}}=0.79, \alpha_{\mathrm{l}}=0.21$ (long chains) and $i_{\mathrm{c}} \approx 30$ (crossover chain length). All indications are that these values carry over to termination of acrylate chain-end radicals at higher, more practical temperatures. Further, these values largely make sense in terms of what is understood about the physical meaning of the parameters. Variation of the rate coefficient for termination between monomeric radicals, $k_{\mathrm{t}}^{1,1}$, is found to be well described by the simple Smoluchowski and Stokes-Einstein equations. This allows easy prediction of $k_{\mathrm{t}}^{1,1}$ for different alkyl acrylates, solvent and temperature. Through all this the unrivalled power of SP PLP EPR for measuring and understanding (chain-length-dependent) termination rate coefficients shines through.

\section{Introduction}

Radical polymerization of acrylates has been studied intensively in recent decades. Most studies have concentrated on butyl acrylate $(\mathrm{BA}),{ }^{[1-13]}$ with this monomer being taken as typical of the entire family. Understanding of the polymerization kinetics of acrylate-type monomers is important not just for scientific reasons, but also because the industrial importance of these monomers makes it essential that their kinetic behavior can be well modeled. This is a real challenge, because the kinetics of acrylates and associated monomers are rather complicated due to the generation and presence of mid-chain radicals (MCRs). ${ }^{[6-8 \text {, }}$ 14, 15] These tertiary radical species are produced via intramolecular transfer to polymer involving a 1,5-H-shift from propagating secondary chain-end radicals (SPRs), a reaction vernacularly known as 'backbiting'. By now it is well known that MCRs are far less reactive when it comes to propagation, ${ }^{[13,16]}$ and the very significant consequences of this are coming to be appreciated.

However the situation is less clear with regard to termination, a reaction that is equally important in terms of prescribing rate and molar mass distribution. The reason for this is not 
just the greater difficulty of measuring termination rate coefficients, ${ }^{[17]}$ but even more so is the sheer complexity of these systems compared with those in which backbiting does not occur. To wit, in acrylate polymerizations there are three different termination reactions contributing to the overall termination rate: SPR homotermination, rate coefficient $k_{\mathrm{t}}^{\mathrm{s}, \mathrm{s}} ; \mathrm{MCR}$ homotermination, $k_{\mathrm{t}}^{\mathrm{t}, \mathrm{t}}$; and SPR-MCR cross-termination, $k_{\mathrm{t}}^{\mathrm{s,t}}$. The contributions of these to the overall termination rate coefficient are governed not just by the respective $k_{\mathrm{t}}$ values, but also by the fraction of MCRs and SPRs that are present.

In fact matters are even more complicated than this, because one should additionally allow for these individual termination rate coefficients to depend on the chain lengths of the radical species involved ${ }^{[18]}$ and, just as importantly, the conversion of monomer into polymer. Not to discount at all the significance of the latter, but it is the former that will be the subject of this paper, in which all measurements are for conversions less than $20 \%$. Various experimental techniques may be used to investigate so-called chain-length-dependent termination (CLDT). The best of these are specially designed methods based on controlling the radical chain length either by laser single-pulse initiation ${ }^{[19-21]}$ or by reversible additionfragmentation (chain-)transfer (RAFT) polymerization. ${ }^{[22]}$ All going well these techniques induce a narrow size distribution of radicals whose degree of polymerization increases linearly with time or conversion respectively. Thus the obtained termination rate coefficients, $k_{\mathrm{t}}^{i, i}$, vary with time and refer to the length, $i$, of radicals present at each instant.

From widespread employment of these methods over the last decade, a remarkably uniform picture of termination at low conversions has emerged. ${ }^{[18]}$ It is that the so-called composite model for termination, Equation $(1),{ }^{[23]}$ seems to be obeyed for all monomers:

$$
\begin{aligned}
& k_{\mathrm{t}}^{i, i}=k_{\mathrm{t}}^{1,1} i^{-\alpha_{\mathrm{s}}}, i \leq i_{\mathrm{c}} \\
& k_{\mathrm{t}}^{i, i}=k_{\mathrm{t}}^{1,1}\left(i_{\mathrm{c}}\right)^{-\alpha_{\mathrm{s}}+\alpha_{1}} i^{-\alpha_{1}}=k_{\mathrm{t}}^{0} i^{-\alpha_{1}}, i>i_{\mathrm{c}}
\end{aligned}
$$


This model postulates that there are (at least) two distinct regimes of chain-length dependence. For short radicals, $k_{\mathrm{t}}^{i, i}$ strongly decreases with $i$, and the exponent $\alpha_{\mathrm{s}}$ is found to be between 0.50 and 0.65 for styrene, methacrylates and some other monomers. This is consistent with termination being controlled by center-of-mass diffusion. For radicals larger in size than a certain crossover chain length $i_{\mathrm{c}}$ of around 50 , the dependency becomes much weaker, with observed values of $\alpha_{1}$ mostly falling in the range $0.15-0.30 .{ }^{[18]}$ Such values are convincingly in accord with O'Shaughnessy's prediction of $\alpha_{1}=0.16$ for control of (longchain) termination by segmental diffusion in a good solvent. ${ }^{[24]}$

The parameter that stimulated the proposal of the composite model is $k_{\mathrm{t}}^{1,1}$, the rate coefficient for termination between two monomeric radicals. The historical issue here may be simply stated: investigations into long-chain termination found that $k_{\mathrm{t}}^{0}$, the apparent value of $k_{\mathrm{t}}^{1,1}$, is of order $10^{8} \mathrm{~L} \cdot \mathrm{mol}^{-1} \cdot \mathrm{s}^{-1}$ in value, ${ }^{[25,26]}$ whereas experiments on monomer-like radicals delivered $k_{\mathrm{t}}^{1,1} \approx 10^{9} \mathrm{~L} \cdot \mathrm{mol}^{-1} \cdot \mathrm{s}^{-1}$, exactly as one would expect from the Smoluchowski equation. ${ }^{[27]}$ As is evident from Equation (1), the composite model resolves this discrepancy

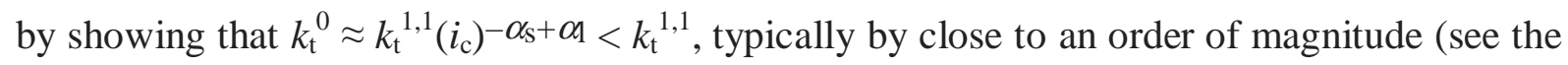
parameter values quoted above). For this reason it is desirable to use experimental methods that can measure true values of ${k_{\mathrm{t}}}^{1,1}$ rather than just $k_{\mathrm{t}}{ }^{0}$ values. Such methods are those already mentioned: ones based on single-pulse pulsed-laser polymerization (SP PLP), ${ }^{[19]}$ RAFT CLDT and SP PLP RAFT. ${ }^{[22]}$

By now these methods have been used to measure $k_{\mathrm{t}}^{1,1}$ for a significant number of systems. Because monomeric radicals are so small, their termination must be via center-ofmass diffusion. Thus from the Smoluchowski equation one expects that

$$
k_{\mathrm{t}}^{1,1}=2 \pi P_{\mathrm{spin}}\left(D_{1}+D_{1}\right) R_{\mathrm{c}} N_{\mathrm{A}}
$$

where $N_{\mathrm{A}}$ is the Avogadro constant, $D_{1}$ is the self-diffusion coefficient for monomer, $R_{\mathrm{c}}$ is the capture separation for termination, and $P_{\text {spin }}$ is the probability of encounter involving a singlet 
pair: on straight statistical grounds this value will be $0.25^{[27,28]}$ The most important quantity in Equation (2) is $D_{1}$. Its behavior should be captured by the well-known Stokes-Einstein equation:

$$
D_{1}=\frac{k_{\mathrm{B}} T}{6 \pi r_{1} \eta}
$$

Here $k_{\mathrm{B}}$ is the Boltzmann constant, $T$ is (absolute) temperature, $r_{1}$ is the hydrodynamic radius of monomer, and $\eta$ is the viscosity of the reaction mixture. For polymerization systems, $\eta$ should be understood as the microviscosity (or solvent viscosity), because it is well known that termination rate coefficients do not vary according to the bulk viscosity. From the above considerations one expects that $k_{\mathrm{t}}^{1,1} \sim\left(r_{1} \eta\right)^{-1}$. Indeed, it has recently been shown that the product $k_{\mathrm{t}}^{1,1} r_{1} \eta$ is remarkably uniform in value for 6 different monomers for which $k_{\mathrm{t}}^{1,1}$ has been confidently measured. ${ }^{[29]}$ Further, the additional expectation that $E_{\mathrm{a}}\left(k_{\mathrm{t}}{ }^{1,1}\right) \approx E_{\mathrm{a}}\left(\eta^{-1}\right)$, where $E_{\text {a }}$ denotes activation energy, is also met astonishingly well where good data exists for the temperature variation of $k_{\mathrm{t}}^{1,1} \cdot{ }^{[29,30]}$ Finally, there are the additional facts that measured values of $k_{\mathrm{t}}^{1,1}$ are in accord with small-molecule measurements ${ }^{[27]}$ and are in broad quantitative agreement with Equation (2). ${ }^{[29]}$ All these findings give confidence that $k_{\mathrm{t}}^{1,1}$ can now be accurately measured and that for many systems these values can largely be understood through the simple framework of the Smoluchowski and Stokes-Einstein equations.

Similar may be said for $\alpha_{\mathrm{s}}$ at low conversion. In order that $k_{\mathrm{t}}^{1,1}$ values can be as high as they are and long-chain values as low as they are, it is necessary that there be a relatively steep decline in $k_{\mathrm{t}}^{i, i}$ at low chain lengths. ${ }^{[23]}$ This prediction of the composite model has been born out for polymerizations with negligible backbiting: as already mentioned, $\alpha_{\mathrm{s}}$ is found to be between 0.50 and 0.65 for methacrylates and styrene, with remarkably good agreement between the values from different experimental techniques. ${ }^{[18]}$ Further, these values of $\alpha_{\mathrm{s}}$ are consistent with the power-law exponents found in measurements of $D_{i}$ as a function of $i$ for 
oligomers. ${ }^{[31,32]}$ Given all this it seems reasonable to say that chain-length-dependent termination at low conversion may now be regarded as well understood for methacrylates and styrene polymerization.

Unfortunately the situation is not so satisfactory for acrylates. To be sure, investigations have been carried out: methyl acrylate (MA), BA and dodecyl acrylate (DA) have all been studied via the techniques of both RAFT CLDT (using dynamic scanning calorimetry to monitor the steady-state rate) and SP PLP RAFT (using NIR spectroscopy to follow the relaxation kinetics). ${ }^{[22,33-35]}$ While full data sets of the composite-model parameters $\alpha_{\mathrm{s}}, \alpha_{\mathrm{l}}, i_{\mathrm{c}}$ and $k_{\mathrm{t}}^{1,1}$ at 60 and $80{ }^{\circ} \mathrm{C}$ have been obtained, physically questionable parameter values were found for $\alpha_{\mathrm{s}}$ especially. To be precise, $\alpha_{\mathrm{s}}>1$ has been returned. While one might expect $\alpha_{\mathrm{s}}=1$ for rod-like chains, for example from charged monomers, such values appear to be unreasonable for flexible acrylate chains.

In this context the first results from using so called SP PLP EPR to investigate acrylate polymerization are very interesting. ${ }^{[13]}$ This technique is SP PLP in which EPR spectroscopy is employed for highly time-resolved monitoring of the kinetics. The advantage for studying acrylates is that one can directly see if the two different types of radical - i.e., MCR and SPR - are present, whereas in the earlier studies with RAFT CLDT and SP PLP RAFT it had to be taken as an article of faith that the observed termination rate was due to SPRs only. From EPR studies it may now be stated with certainty that at 60 and $80{ }^{\circ} \mathrm{C}$, the fraction of MCRs in BA polymerization is around $80 \% .{ }^{[12]}$ Thus it seems likely that the previously reported $\alpha_{\mathrm{s}}$ values for acrylates are artifacts from the presence of MCRs, meaning that the measured values of $k_{\mathrm{t}}^{i, i}$ contained significant contributions also from $k_{\mathrm{t}}^{\mathrm{t}, \mathrm{t}}$ and $k_{\mathrm{t}}^{\mathrm{s}, \mathrm{t}}$. Indeed, when Barth et al. reduced the temperature to a level where only SPRs were found to be present, they obtained the more reasonable value of $\alpha_{\mathrm{s}}=0.85$ for $\mathrm{BA} .{ }^{[13]}$ This finding indicates that the earlier acrylate work using the RAFT techniques to investigate CLDT must be repeated using SP 
PLP EPR at very low temperature. This is what will be done in this work, with the aim of determining composite-model termination parameters that unambiguously apply to SPRs.

Even without the ambiguity caused by the presence of MCRs in the earlier studies, there would still be good reason to investigate acrylate termination using SP PLP EPR. There is the general consideration that this method is held to be the best available method for probing CLDT, ${ }^{[17]}$ because it directly measures radical concentration, as opposed to doing so indirectly via conversion-time measurements. It also has specific advantages over the RAFTbased methods, namely: SP PLP EPR does not rely on increasing conversion to effect change in chain length, but instead can deliver $k_{\mathrm{t}}^{i, i}$ at a constant conversion; and in SP PLP EPR there is not the complicating possibility of a contribution to the overall rate of termination in cases where cross-termination between the RAFT intermediate and propagating radicals occurs. Also for these reasons it is justified to use SP PLP EPR to put the previous work on a more solid footing.

In the present work we apply SP PLP EPR to study chain-length-dependent termination of acrylates at $\theta \leq-30{ }^{\circ} \mathrm{C}$, where the impact of MCRs on termination rate is negligible. ${ }^{[13]}$ A virtue of SP PLP EPR is that it may be carried out at such temperatures since the signal-to-noise ratio is still good, whereas this is not the case for methods such as the RAFT-based ones that measure monomer conversion. A criticism of this approach is that it does not yield results that are directly applicable to commercial polymerization temperatures. The counter argument to this is firstly that there is no other choice: at higher temperatures there is no possibility of unambiguous extraction of all individual termination rate coefficients even from SP PLP EPR data, ${ }^{[13]}$ let alone from techniques that measure only polymerization rate. Therefore the only way to proceed is to start with conditions where only SPRs are present, and to build up from this foundation. In earlier times it was the same story with propagation rate coefficients, $k_{\mathrm{p}}$ : progress in unraveling the cloudy picture at higher temperatures was only made once $k_{\mathrm{p}}$ for SPRs was unambiguously measured at the same low 
temperatures as employed here. ${ }^{[6]}$ The second aspect of the counter argument is that in our earlier study of BA termination in toluene using SP PLP EPR it was found that $\alpha_{\mathrm{s}}, \alpha_{\mathrm{a}}$ and $i_{\mathrm{c}}$ are relatively constant with temperature, ${ }^{[13,29,30,36]}$ and thus the values found at low temperature serve as reasonable estimates for higher temperatures. It was further found that $E_{\mathrm{a}}\left(k_{\mathrm{t}}{ }^{1,1}\right) \approx E_{\mathrm{a}}\left(\eta^{-1}\right)$ for $\mathrm{BA}$ SPRs, ${ }^{[13]}$ which means that values of $k_{\mathrm{t}}^{1,1}$ measured at low temperatures may easily be extrapolated to higher temperatures: all one needs to know is the temperature dependence of the fluidity of the reaction medium, which may easily be measured if it is not available in the literature. Therefore the low temperature experiments presented in the present paper serve for adequate estimation of SPR self-termination rate coefficients at higher temperatures where direct measurement of $k_{\mathrm{t}}^{i, i}$ for SPR homotermination is not yet possible due to the occurrence of MCRs.

In particular in this work we are interested to find out whether the abnormally high values of $\alpha_{\mathrm{s}}$ found for acrylates using the RAFT-based techniques are real or flawed.

\section{Experimental Part}

The monomers methyl acrylate (MA; $99 \%$, stabilized with hydroquinone monomethyl ether, Aldrich), $n$-butyl acrylate (BA; > 99.5\%, stabilized with hydroquinone monomethyl ether, Fluka) and dodecyl acrylate (DA) (90\% technical grade, stabilized with hydroquinone monomethyl ether, Aldrich) were purified by passing through a column filled with inhibitor remover (Aldrich). The solvent toluene $(99.5 \%$, Fluka) was used without further purification. The polymerization solutions were degassed by several freeze-pumpthaw cycles. For polymerizations in solution with toluene, larger sample volumes could be used as compared with polymerizations in bulk. Sample volumes of $0.20 \mathrm{~mL}$ were filled into EPR tubes of $5 \mathrm{~mm}$ outer and $4 \mathrm{~mm}$ inner diameter, while for volumes of $0.05 \mathrm{~mL}$ these tube dimensions were $3 \mathrm{~mm}$ and $2 \mathrm{~mm}$ respectively. The photoinitiator $\alpha$-methyl- 
4(methylmercapto)- $\alpha$-morpholinopropiophenone (MMMP; $98 \%$, Aldrich) was used as received. It was added to the degassed monomer solutions in a glove box under an argon atmosphere so as to give initial MMMP concentrations of about $1.6 \times 10^{-2} \mathrm{~mol} \cdot \mathrm{L}^{-1}$.

The EPR tubes were fitted into the EPR resonator cavity. The samples were irradiated through a grid by a COMPex 102 excimer laser (Lambda Physik) operated on the XeF line $(351 \mathrm{~nm})$ at laser energies between 10 and $80 \mathrm{~mJ}$ per pulse. The EPR spectrometer and the laser source were synchronized by a pulse generator (Scientific Instruments 9314). Temperature control was achieved via an ER 4131VT unit (Bruker) after purging the sample cavity with nitrogen. The SP PLP EPR setup has previously been described in full. ${ }^{[29]} \mathrm{A}$ Bruker Elexsys E 500 series cw-EPR spectrometer was used for the experiments. Typical EPR parameter settings were as follows: $3 \mathrm{G}$ field modulation amplitude, $100 \mathrm{kHz}$ field modulation frequency, 3 to $10 \mathrm{~mW}$ microwave power, and time constant $0.01 \mathrm{~ms}$. It was carefully checked that no saturation of the EPR signals occurred.

\section{INSERT Figure 1}

Each experiment was begun with a $10 \mathrm{~s}$ period of polymerization with laser pulsing rate of $20 \mathrm{~Hz}$. This was to generate a high and relatively constant radical concentration for recording a full EPR spectrum (sweep time of $10 \mathrm{~s}$ ). Because of the brevity of this period, there was no significant monomer conversion at this stage. Figure 1 presents a typical such EPR spectrum from this work. The first purpose of these spectra is to identify the radicals present. It can be seen in Figure 1 that the chain-end radicals (SPRs), which give rise to the 4 broad lines, ${ }^{[12]}$ strongly dominate the spectrum at these low temperatures. The MCR line positions that are known from EPR spectra at higher temperatures ${ }^{[10,12]}$ are also indicated in the figure. The absence of any significant signal at any of these line positions evidences that the MCR contribution to termination rate must be negligible.

The second purpose of recording a full EPR spectrum is to identify an optimum magnetic field position for measurement of radical concentration, $c_{\mathrm{R}}$. For the case of Figure 1, 
this position is marked by the arrow. From the strength of the signal at this position one may determine $c_{\mathrm{R}}$. Thus measurement of $c_{\mathrm{R}}$ on a microsecond timescale is possible, because one does not need to sweep over a range of field strengths. This enables $c_{\mathrm{R}}$ to be obtained with the necessary rapidity for SP PLP. To improve the signal-to-noise in $c_{\mathrm{R}}(t)$ for an SP PLP, the individual traces from up to 50 consecutive experiments (with a gap of 15-20 s between laser pulses) were co-added. Final conversions, determined gravimetrically, were always less than $20 \%$. In no case did increasing conversion alter the individual $c_{\mathrm{R}}(t)$ traces. Absolute radical concentration was obtained by setup calibration for each specific reaction mixture, as described in detail elsewhere. ${ }^{[29]}$

Kinematic viscosities, $v$, were measured using a calibrated KPG Ubbelohde microviscosimeter (Schott $\mathrm{GmbH}$ ) and corrected via the Hagenbach-Couette procedure. Mixture densities, $\rho$, as a function of temperature, $T$, were measured using a density meter (Anton Paar, DMA 60). Dynamic viscosities, $\eta$, were calculated via $\eta=v / \rho$. Values of $v, \eta$ and $\rho$ are tabulated in the Supporting Information.

\section{Data Analysis and Results}

To obtain values of the composite-model parameters $k_{\mathrm{t}}^{1,1}, \alpha_{\mathrm{s}}, \alpha_{\mathrm{l}}$ and $i_{\mathrm{c}}$ (see Equation (1)) from our experimental $c_{\mathrm{R}}(t)$ data we used the following procedure. ${ }^{[37]}$ First, the data were plotted as $\log \left(c_{\mathrm{R}}{ }^{0} / c_{\mathrm{R}}-1\right)$ versus $\log t$, where $c_{\mathrm{R}}{ }^{0}$ is the value of $c_{\mathrm{R}}$ immediately after the laser pulse. The rationale for this approach ${ }^{[38]}$ is the equation

$$
\frac{c_{\mathrm{R}}^{0}}{c_{\mathrm{R}}}-1=\frac{2 c_{\mathrm{R}, 0} k_{\mathrm{t}}^{1,1}\left(k_{\mathrm{p}} c_{\mathrm{M}}\right)^{-\alpha}}{(1-\alpha)} t^{1-\alpha}
$$

where $k_{\mathrm{p}}$ is the propagation rate coefficient and $c_{\mathrm{M}}$ is the monomer concentration. Equation (4) assumes a single power-law dependence of $k_{\mathrm{t}}^{i, i}$ on $i$ and that $i \gg 1 .^{[39]}$ It suggests looking 
for linear regions in a plot of $\log \left(c_{\mathrm{R}}{ }^{0} / c_{\mathrm{R}}-1\right)$ versus $\log t$, and taking the slope of these as $1-\alpha$, from which it is trivial to determine $\alpha^{[38]}$

\section{INSERT Figure 2}

An example of this procedure is given in Figure 2. Two straight-line regions are evident, suggesting composite-model behavior. ${ }^{[38]}$ From the long-time slope the value of $\alpha_{1}$ is obtained, while the crossover chain length $i_{\mathrm{c}}=t_{\mathrm{d}}\left(k_{\mathrm{p}} c_{\mathrm{M}}\right)$ is determined from $t_{\mathrm{c}}$, the time at which the two straight lines intersect. However only an estimate of $\alpha_{\mathrm{s}}$ may be obtained from the slope of the linear fit at short times. This is because the assumption $i \gg 1$ breaks down at very early times, necessitating use of the following equation that accounts for radicals having a non-zero length at $t=0:^{[39]}$

$$
\frac{c_{\mathrm{R}}^{0}}{c_{\mathrm{R}}}-1=\frac{2 c_{\mathrm{R}}^{0} k_{\mathrm{t}}^{1,1}}{k_{\mathrm{p}} c_{\mathrm{M}}\left(1-\alpha_{\mathrm{s}}\right)}\left[\left(k_{\mathrm{p}} c_{\mathrm{M}} t+1\right)^{1-\alpha_{\mathrm{s}}}-1\right]
$$

This equation is curved when plotted as $\log \left(c_{\mathrm{R}}{ }^{0} / c_{\mathrm{R}}-1\right)$ versus $\log t$; specifically, it has a downward curvature at very early times, a trend evident in the data of Figure 2 and which cannot be accounted for via straight-line fitting and the use of Equation (4), a procedure which therefore results in systematic underestimation of $\alpha_{\mathrm{s}}$ values. ${ }^{[39]}$ Instead one should carry out non-linear least-squares fitting of Equation (5) to early-time data, as exemplified in Figure 3. It is evident that a complete description of data right through to $t=t_{\mathrm{c}}$ is provided.

INSERT Figure 3

The fitting procedure of Equation (5) yields the exponent value for short radicals, $\alpha_{\mathrm{s}}$, typically to an error margin of comfortably less than 0.1 , as is demonstrated in Figure 3 by the data-encompassing dashed lines. Nevertheless we estimate that our procedure yields $\alpha_{\mathrm{s}}$ only to within \pm 0.1 . This is largely on account of chain-length-dependent propagation (CLDP) not being taken into account. This is for two reasons: ${ }^{[39]}$ (1) There is no straightforward way of achieving this. (2) Even if an easily deployed description like Equation (5) were available, 
there is no certainty as yet over the form of CLDP to employ in it. Of course CLDP is restricted to very small $i$, and indeed, it is noticeable in Figure 3 that the experimental points for $t<0.001 \mathrm{~s}-$ corresponding to chain lengths below $i \approx 5-$ all lie just above the fits of Equation (5). Nevertheless there is no reason to expect that this small systematic discrepancy at early times should greatly impact upon the value of $\alpha_{\mathrm{s}}$ that is returned by fitting Equation (5) over the much larger time interval of the data as a whole. This is why we estimate the error in $\alpha_{\mathrm{s}}$ as being \pm 0.1 .

Equation (5) makes clear that the fitting procedure also returns monomeric-radical termination rate coefficients $k_{\mathrm{t}}^{1,1}$ as the coupled quantity $k_{\mathrm{t}}^{1,1} \cdot c_{\mathrm{R}}^{0}$. The maximum radical concentration, $c_{\mathrm{R}}{ }^{0}$, is obtained from the signal intensity directly after single laser pulsing, $I(0)$. However determination of this quantity is complicated in some cases by experimental issues: perturbation of the EPR cavity by the laser pulse at $t=0$ and the limited time-resolution combined with the fast signal decay in the initial SP-PLP period lead to an underestimation of $c_{\mathrm{R}}{ }^{0[13,36]}$ To account for the resulting systematic error in $I(0)$, the highest value of $I(0)$ measured within each series of SP PLP EPR experiments under identical conditions was implemented for data evaluation. This typically results in an upward correction of $c_{\mathrm{R}}{ }^{0}$ by a factor of two and a great enhancement of the fitting quality. It needs to be mentioned that by further elevation of $I(0)$ the fit quality is reduced. The results for $\alpha_{\mathrm{s}}$ are only weakly influenced by the selection of $I(0)$. On the other hand, the error margin in $k_{\mathrm{t}}^{1,1}$, which is essentially given by the quality of calibrating radical concentration, has been conservatively estimated to be $30 \%$ on the basis of the above limitations. While this may seem disappointing, it has to be seen in the context of ${k_{\mathrm{t}}}^{1,1}$ being difficult to measure at all: ${ }^{[18]}$ in fact the present values are highly accurate and precise by historical standards.

\section{INSERT Table 1}

Composite-model parameter values obtained as above are given in Table 1. The data refer to average values from up to five individual experiments under identical experimental 
conditions. The error is estimated from the scatter in the fitting results within a certain experimental series. For fitting of Equation (5), the following estimates of bulk $k_{\mathrm{p}}$ at $-40{ }^{\circ} \mathrm{C}$ were used, as obtained from reported Arrhenius parameters: MA: ${ }^{[40]} 2130 \mathrm{~L} \cdot \mathrm{mol}^{-1} \cdot \mathrm{s}^{-1}$; $\mathrm{BA}:^{[41]} 2270 \mathrm{~L} \cdot \mathrm{mol}^{-1} \cdot \mathrm{s}^{-1}$; DA: $1365^{[42,}{ }^{43]}$ (estimate for toluene solution) and 2730 $\mathrm{L} \cdot \mathrm{mol}^{-1} \cdot \mathrm{s}^{-1}{ }^{[40]}$ These values will be discussed in the following section. Values of $c_{\mathrm{M}}$ for fitting of Equation (5) were calculated from zero-conversion densities; this is justified because final experimental conversions were kept relatively low (see the Experimental Part).

\section{Discussion}

First of all it is necessary to say something about the $k_{\mathrm{p}}$ values used in data analysis, as just given. The issue is that some measurements were in bulk, others in toluene solution. Normally one would confidently use bulk $k_{\mathrm{p}}$ values also for toluene solution polymerizations. However Buback $^{[42]}$ has recently drawn attention to, and given a mechanistic explanation for, the fact that there seem to be systematic differences between acrylate $k_{\mathrm{p}}$ in bulk and in toluene solution. ${ }^{[43]}$ Specifically, starting from the position of $k_{\mathrm{p}}$ being much the same for MA under both sets of conditions, in toluene solution it decreases with increasing alkyl-group size, whereas in bulk there is the expected ${ }^{[44]}$ increase $^{[42]}$ These trends are sufficiently marked that for DA they seem to result in the bulk value of $k_{\mathrm{p}}$ being double that in toluene solution. ${ }^{[42]}$

For these reasons we used the bulk MA value of $k_{\mathrm{p}}$ to analyze both our bulk and solution data, whereas for DA in toluene we estimated $k_{\mathrm{p}}$ to be half the bulk value, and it is the resulting termination parameters that we assume are more likely to be correct in the discussion that follows. At the same time, we also analyzed our DA data with the much higher bulk value of $k_{\mathrm{p}}$, because we recognize that there is still considerable uncertainty regarding the

finding - based on one toluene data set only ${ }^{[43]}$ - that acrylate $k_{\mathrm{p}}$ have a quite different variation with size in toluene than in bulk: this has not been established definitively and is an interesting area requiring further work. The termination parameters resulting from this 
alternative analysis are the ones in brackets in Table 1 . They are included to give an idea of the uncertainty introduced by this uncertainty in $k_{\mathrm{p}}$, which has a strong effect on $i_{\mathrm{c}}$ values in particular. This should be borne in mind during the discussion that now follows, including that this uncertainty may also apply to other acrylates to some extent.

As well as results from this work, Table 1 also presents literature values of compositemodel parameters at higher temperatures using the two RAFT-based techniques outlined in the Introduction. It is evident that the four parameters $\alpha_{\mathrm{s}}, \alpha_{\mathrm{l}}, i_{\mathrm{c}}$ and $k_{\mathrm{t}}^{1,1}$ have now been measured for all three acrylates by three different techniques. Further, the SP PLP EPR technique has been deployed for bulk and solution conditions, with the only gap in the table being for bulk DA at $-40{ }^{\circ} \mathrm{C}$, where polymerizations are not possible because the monomer is solid (its melting point is about $4{ }^{\circ} \mathrm{C}$, at which temperature there would be significant $\mathrm{MCR}$ formation). Table 1 thus represents a comprehensive body of data on acrylate termination and demands detailed discussion.

The first thing to say is that methacrylate studies have shown that all else being equal, one can expect SP PLP EPR and RAFT CLDT to yield composite-model termination parameters that are in near perfect agreement. ${ }^{[30,45]}$ This suggests that any of the peculiarities of RAFT polymerization - such as cross-termination of the RAFT intermediate or variation of $k_{\mathrm{t}}^{i, i}$ with conversion - appear to have no significant effect on determination of $k_{\mathrm{t}}^{i, i}$. Thus any discrepancies in Table 1 should not be due to the methods themselves but should find explanation in other factors.

The main purpose of this manuscript is to explain the abnormally high $\alpha_{\mathrm{s}}$ values found via RAFT-mediated acrylate polymerizations. Therefore this is the first parameter that will be scrutinized. Table 1 reminds that $\alpha_{\mathrm{s}}$ values significantly above 1.0 have been found via RAFT CLDT and SP PLP RAFT for BA and DA. Pleasingly, significantly lower values for BA and DA have been obtained by the SP PLP EPR technique within the present study: $\alpha_{\mathrm{s}}$ for all three acrylates fall within the range $0.71-0.87$. 
From the theoretical side one may expect $\alpha_{\mathrm{s}}$ to be related to the decrease of a radical's center-of-mass diffusion coefficient, $D$, with degree of polymerization. Amongst other things this is linked to increasing size. By considering excluded volume effects on the polymer chain structure in a good solvent, theory predicts $D_{i} \sim i^{-0.6}{ }^{[46]}$ Measurements of diffusion coefficients as a function of chain length for oligomeric species of methyl methacrylate $(\mathrm{MMA}),{ }^{[31]} n$-butyl methacrylate (BMA) ${ }^{[31]}$ 2-hydroxyethyl methacrylate ${ }^{[47]}$ and styrene ${ }^{[32]}$ have been carried out by pulsed-field-gradient NMR and have resulted in power-law exponents of $-0.66,-0.66,-0.66$ and -0.51 , respectively, in dilute solution. To the best of our knowledge the literature contains no such chain-length-dependent diffusion coefficients for acrylate oligomers.

Despite this absence of specific data, one may still say that there is no obvious reason that $\alpha_{\mathrm{s}}$ for an acrylate should be grossly different to the value for the corresponding methacrylate, because in both cases there will be the same general coil structure, although the greater flexibility of the acrylate species might conceivably impart some minor difference. For methacrylate polymerizations, representative $\alpha_{\mathrm{s}}$ values are $0.63^{[30]}$ and $0.65^{[45]}$ for MMA (obtained via SP PLP EPR and RAFT CLDT respectively), 0.65 for BMA, ${ }^{[36]} 0.50$ for benzyl methacrylate $^{[37]}$ and 0.64 for dodecyl methacrylate (DMA). ${ }^{[37]}$ All of these values are remarkably close to those quoted above from diffusion studies, noting that benzyl methacrylate, with its cyclic pendant group, should be like styrene.

In the SP PLP EPR results of this work, no definite variation of $\alpha_{\mathrm{s}}$ with acrylate or with solvent is discernible (see Table 1). There is a suspicion of $\alpha_{\mathrm{s}}$ increasing with increasing alkyl group size in the toluene values, but the opposite is observed in bulk. Further, a lack of variation with length of $n$-alkyl group is expected on the basis of the methacrylate values quoted above. Nevertheless this is obviously an area requiring more thorough experimental examination, especially into whether solvent has an impact on $\alpha_{\mathrm{s}}$. In the meantime it appears 
justified to average the $5 \alpha_{\mathrm{s}}$ values of this work and recommend the resulting value, $\alpha_{\mathrm{s}}=$ $0.79 \pm 0.10$, as a universal short-chain exponent for termination of $n$-alkyl acrylate SPRs. This value is higher than those of the analogous methacrylates (see above) by a small but nevertheless statistically genuine extent. It would be of great interest to know if this high $\alpha_{\mathrm{s}}$ value is reflected in the variation of $D$ with $i$ for acrylate oligomers, and so measurement of such $D$ values is suggested as a matter requiring urgent attention.

The values $\alpha_{\mathrm{s}}>1$ found in BA and DA polymerization via the RAFT techniques (see Table 1) presumably result from a significant contribution of MCR self- and cross-termination at the higher temperatures of these experiments. The most likely mechanism here is as follows: MCRs are characterized by significantly slower termination than SPRs, ${ }^{[8,13]}$ which means that as MCRs form, the overall termination rate is naturally lowered. This expresses itself as stronger reduction in overall $k_{\mathrm{t}}$ with time than that due to increase of SPR chain length alone, meaning that an anomalously high $\alpha_{\mathrm{s}}$ is returned - one that reflects both the decrease of $k_{\mathrm{t}}^{i, i}$ with SPR chain length and the conversion of some SPRs into more slowly terminating MCRs.

In this context the remarkable coincidence of $\alpha_{\mathrm{s}}$ values for bulk MA -0.80 in the present study versus $0.78^{[48]}$ and $0.78^{[34]}$ via the RAFT-based methods - should be discussed. Why is there this agreement with MA but not with BA and DA? There are various possibilities, several of which may act together: (i) Termination is faster in MA systems (because $k_{\mathrm{t}}^{1,1}$ is higher, see below), meaning that the radical population available for backbiting is lower, making it a less important process in termination experiments. (ii) The backbiting rate coefficient for MA is significantly lower than for BA and DA, meaning that the MCR concentration is lower and therefore does not influence termination kinetics as much. (iii) Propagation of mid-chain radicals is faster for MA than BA and DA because of the monomer concentration being higher, hence as in (ii). (iv) The RAFT results for MA are 
fortuitous. Assessing all these possible explanations, (ii) seems highly unlikely, because it is hard to imagine that MCRs do not play a major role in MA kinetics at $50{ }^{\circ} \mathrm{C}$ and above. However there must be truth to explanations (i) and (iii), while (iv) remains a distinct possibility.

Next we examine the $\alpha_{\mathrm{l}}$ values of Table 1. There are two relevant pieces of background theory here: (1) For encounter by segmental motion in a good solvent, theory predicts $\alpha_{1}=0.16$ for the ends of long chains, 0.43 for the middles of long chains, and 0.27 for the end of a long chain with the middle of a long chain. ${ }^{[24]}$ (2) It has recently been confirmed that where the reactive site is somewhere between the middle and the end of a long chain, $\alpha_{1}$ will be between the limiting values just quoted. ${ }^{[49,50]}$ For example, for termination of an endchain radical with a mid-chain radical, $\alpha_{1}$ increases from 0.16 to 0.27 as the radical site progresses from the end of the chain to the middle.

In view of these findings one would expect to observe $\alpha_{1} \approx 0.16$ for our SP PLP EPR results, where only SPRs should be present, and $\alpha_{1}>0.16$ for the RAFT-based techniques, where MCRs will also have been present. What is observed? The first surprise is that Table 1 reveals no discernible variation in $\alpha_{\mathrm{l}}$ : the average of the 6 values from the RAFT techniques at higher temperature is $\alpha_{1}=0.21$, while the average of the 5 values from SP PLP EPR at lower temperature is also 0.21 . These values make clear the second surprise, which is that while $\alpha_{1}$ is close to the theoretical value of 0.16 , possibly within the margin of experimental error, it is more likely that it is in fact slightly higher. Taken together these values recommend using $\alpha_{1}=0.21$ as a universal value for $n$-alkyl acrylate termination. In an absolute sense this value is close to theoretically expected value of 0.16 , but in a relative sense it is different, enough that it may indicate a real effect.

It is easier to find possible explanations for the first surprise above. One is that the socalled "mid-chain radical" is actually so close to the chain end (to be precise, it is the length 
of one butyl group away) that in terms of segmental motions it is like an end-chain radical. So in some sense the term mid-chain radical is a misnomer: it is not meant to convey that the radical is in the middle of the chain, but simply that it is not precisely at the chain end, and therefore it has different kinetic behavior - in particular in terms of $k_{\mathrm{p}}$ - than if it were an SPR. There is also the aspect that once an SPR becomes an MCR, its growth is stalled, and thus the correlation between time and chain length that is so essential to SP PLP and RAFT CLDT is lost. This is yet to be explored by kinetic simulations, but it is easy to imagine that the constant rate of termination due to being frozen in chain length acts to counterbalance any raising of $\alpha_{1}$ due to the radical no longer being at the end of the chain. Either or both of these reasons may well contribute to experiments with MCRs delivering $\alpha_{1}$ the same as in experiments without MCRs.

The second surprise is harder to rationalize. Remembering that theories for $\alpha_{1}$ all assume that chains are topologically linear rather than having pendant groups, at first it seems reasonable to speculate that a higher $\alpha_{1}$ may be caused by the radical not being positioned perfectly at the chain-end even in an SPR, by virtue of the presence of an ester side-chain next to it. Thinking of the simulations of Fröhlich et al. (see background point (2) above), ${ }^{[49,50]}$ one might postulate that this causes $\alpha_{1}$ to be elevated slightly above 0.16 . However this suggestion runs into problems. One is that it should carry over to the methacrylates, but for this family it is not observed: $\alpha_{\mathrm{l}}$ for MMA, BMA and DMA are all essentially equal to $0.16^{[18]}$ The second issue is that if this suggestion is correct, then the effect should be considerably stronger for DA - with such a long alkyl group - than for MA, however there is no hint of such a trend in the data of Table 1. Nevertheless one should not be unduly troubled by this point. As a sage physical chemist would say, the data should not be overinterpreted. Not only is the discrepancy between 0.16 and 0.21 small, but if one reflects it is actually quite remarkable 
that the field of chain-length-dependent termination has advanced so far that there can be serious discussions over a point such as this. ${ }^{[18]}$

The next parameter in Table 1 is the crossover chain length $i_{\mathrm{c}}$. At the outset it needs to be stated that it is difficult to obtain this parameter value with high precision: Figure 2 illustrates that the crossover between linear regimes in the data is not sharp. So the following discussion, while justified, is speculative in parts.

The first point to note is that the $i_{\mathrm{c}}$ values from SP PLP EPR are slightly higher on average than those from the RAFT methods. This is most likely just an artifact of the RAFT methods returning $\alpha_{\mathrm{s}}$ values that are too high, as already discussed. This may be compensated for by $i_{\mathrm{c}}$ being too small, so that the artificially strong decline in $k_{\mathrm{t}}^{i, i}$ is arrested at an earlier point. If this explanation is correct, then the SP PLP EPR values of $i_{\mathrm{c}}$ should be regarded as being closer to the true ones.

The second point is that there is considerable variation of the $i_{\mathrm{c}}$ values from SP PLP EPR: three are within the range $30 \pm 5$, which is at the upper end of the RAFT values (range of $18-30)$, while two are clearly higher (65 and $50-100)$. It is not possible to ascribe this situation either to monomer or to solvent, as these high values were obtained for different acrylates, while one was obtained in toluene and the other in bulk. So at the moment we have no convincing explanation for these differences, and must simply conclude that more precise measurements and more precise $k_{\mathrm{p}}$ values (see discussion above) are required in order to establish the situation definitively. This will become possible as better EPR instruments are used and as solvent effects on $k_{\mathrm{p}}$ are investigated more systematically.

Even allowing for this uncertainty, it seems reasonable to conclude on the basis of the Table 1 data in toto that $i_{\mathrm{c}}$ for acrylates are most likely in the range $20-50$, which means they are smaller than for methacrylates, where values in the range 50 - 100 have been measured by the different techniques of Table $1 .{ }^{[18]}$ Once again one is struck by the fact that where $\alpha_{\mathrm{s}}$ is higher (acrylates), $i_{\mathrm{c}}$ is lower, meaning that the overall termination rate is not as much 
lowered by the higher $\alpha_{\mathrm{s}}$ value as it might be, due to the earlier switchover to the long-chain regime in which CLDT is rather mild (i.e., $\alpha_{\mathrm{l}}$ relatively close to zero). For systems studied so far this seems to be a trend in nature whereby $k_{\mathrm{t}}^{i, i} / k_{\mathrm{t}}^{1,1}$ values are homogenized.

The most obvious explanation for the family trend in $i_{\mathrm{c}}$ values is that this quantity is related to glass transition temperature: ${ }^{[36]}$ the $T_{\mathrm{g}}$ values of polymethacrylates are typically 50 $100{ }^{\circ} \mathrm{C}$ greater than the corresponding polyacrylate values. ${ }^{[51]}$ This means that at a given temperature the acrylates are more flexible, which should allow them to start behaving as long chains at a lower chain length, and hence have a lower $i_{\mathrm{c}}$.

About this simple but attractive argument there are two further points to make. The first is that methacrylate measurements of $i_{\mathrm{c}}$ have generally been at considerably higher temperature than that of this work for the measurement of $i_{\mathrm{c}}$. Since chain flexibility is related to temperature, strictly speaking one needs to compare methacrylate and acrylate $i_{\mathrm{c}}$ values at the same temperature in order to test the present hypothesis. In this respect it is interesting that at the lower temperature of this work, where chains are stiffer, $i_{\mathrm{c}}$ seems to be higher than at the higher temperatures of the RAFT measurements, where chains would have been more flexible: this is in accord with present thinking. This discussion makes clear the desirability of being able to measure how $i_{\mathrm{c}}$ varies with temperature, something that has not yet been attempted.

The second point concerns the possible connection between $i_{\mathrm{c}}$ and entanglement formation. This too is an attractive hypothesis, i.e., that $i_{\mathrm{c}}$ reflects the size at which chains become entangled. ${ }^{[36]}$ The problem with this idea is that under dilute-solution conditions chains are not entangled at all, and yet 'normal' $i_{\mathrm{c}}$ values have always been measured under such conditions. A way to explain this is if $i_{\mathrm{c}}$ is related to transient entanglement formation as two terminating chains overlap. However this interpretation is problematic, because entanglements are a many-chain phenomenon, not a pairwise one. Further, in no study to date has a variation of $i_{\mathrm{c}}$ with conversion been detected, whereas if this quantity is related to 
entanglement formation then it should definitely decrease in value as more polymer is formed. So any connection between $i_{\mathrm{c}}$ and entanglements remains questionable.

Within the family of methacrylate monomers, $i_{\mathrm{c}}$ of 100 has been found for MMA, ${ }^{[45]}$, 70 for tert-BMA, 50 for $n$-BMA ${ }^{[36]}$ and 50 for DMA. ${ }^{[37]}$ This trend is nicely consistent with $T_{\mathrm{g}}$ values, which of course decrease - meaning greater chain flexibility - as the size and linearity of the pendant group increase. ${ }^{[36]}$ In fact $T_{\mathrm{g}}$ decreases by more than $150{ }^{\circ} \mathrm{C}$ in going from $\mathrm{p}$ (MMA) to $\mathrm{p}(\mathrm{DMA}){ }^{[51]}$

Referring to Table 1, if anything the opposite trend in $i_{\mathrm{c}}$ values is observed here for acrylates, i.e., our values increase as the alkyl group becomes larger. To some extent this probably reflects the different variation of $T_{\mathrm{g}}$ within the acrylate family: first of all it decreases with increasing alkyl group length (as with the methacrylates) before reaching a minimum close to $\mathrm{p}(\mathrm{BA})$ and then increasing, with the result that $\mathrm{p}(\mathrm{MA})$ and $\mathrm{p}(\mathrm{DA})$ have very similar $T_{\mathrm{g}}$ values. This leads to the expectation that $i_{\mathrm{c}}$ should be about the same for $\mathrm{p}(\mathrm{MA})$ and $\mathrm{p}(\mathrm{DA})$ and slightly smaller for $\mathrm{p}(\mathrm{BA})$. This is not observed in the present results, although the $i_{\mathrm{c}}$ values from the RAFT studies are consistent with the suggestion of limited variation of $i_{\mathrm{c}}$ from acrylate to acrylate. Probably the just-described situation with SP PLP EPR reflects that intra-family variation of $i_{\mathrm{c}}$ is determined by more than just $T_{\mathrm{g}}$, although resolving this will have to wait until $i_{\mathrm{c}}$ is measured more precisely.

The fact that the correlation of $i_{\mathrm{c}}$ with $T_{\mathrm{g}}$ is not universal can be emphasized as follows. $\mathrm{P}(\mathrm{DMA})$ has $T_{\mathrm{g}}=-65{ }^{\circ} \mathrm{C}$ and $i_{\mathrm{c}} \approx 50 .{ }^{[37]}$ All the acrylates of this work have $T_{\mathrm{g}}$ higher than this, and yet most acrylate $i_{\mathrm{c}}$ measurements have been lower (see Table 1). This establishes the not surprising point that $i_{\mathrm{c}}$ must be determined by more than one effect, for example steric hindrance (increasing as pendant alkyl groups become larger) might also somehow be involved. Nevertheless it seems undeniable that the notion of chain stiffness, as reflected in $T_{\mathrm{g}}$, is highly successful in explaining many trends in $i_{\mathrm{c}}$ values. 
The last parameter to be discussed is $k_{\mathrm{t}}^{1,1}$. As already explained in the Introduction, for many systems its value is related to (zero-conversion) viscosity. To attempt to rationalize our $k_{\mathrm{t}}^{1,1}$ values, we therefore measured $\eta$ as function of temperature. This data is available in the Supporting Information, including Arrhenius plots. The resulting activation energies for $\eta^{-1}$ and values of $\eta$ from extrapolation to $-40{ }^{\circ} \mathrm{C}$, the temperature of this work, are reported in Table 2 (note that it was not possible for us to measure $\eta$ at $-40{ }^{\circ} \mathrm{C}$ directly).

\section{INSERT Table 2}

As usual we begin by comparing our SP PLP EPR results with those from the RAFT methods. The latter values have been adjusted to the temperature and (where necessary) the pressure of this work. Table 1 shows that the $k_{\mathrm{t}}^{1,1}$ values from EPR are generally lower than those from RAFT, although it is only with the BA results that one might consider this a significant trend. Really the MA and DA results are in acceptable agreement across methods, and even with the BA values it is not unreasonable to ascribe the variation to scatter. There is no obvious reason why there should be methodological variation of $k_{\mathrm{t}}^{1,1}$. If anything the formation of MCRs at higher temperatures might lead to lower $k_{\mathrm{t}}^{1,1}$, because of the slower termination of small MCRs. ${ }^{[13]}$ Then again, the slow propagation of such MCRs will act to elevate termination rates by keeping the radicals short, which might lead to overestimation of $k_{\mathrm{t}}^{1,1}$. As these statements imply, it has not yet been thoroughly and specifically investigated via simulations how MCR formation affects the values of termination parameters obtained by CLDT methods. Most likely any variations of ${k_{\mathrm{t}}}^{1,1}$ with method in Table 1 are just random scatter. In many ways it is remarkable even to be discussing differences in $k_{\mathrm{t}}^{1,1}$ that are so small by historical standards. One should not forget that $k_{\mathrm{t}}^{1,1}$ remains difficult to measure with high precision and has a significantly higher relative error than $\alpha_{\mathrm{s}}$ and $\alpha_{\mathrm{l}}$.

We now turn to considering the trends in our $k_{\mathrm{t}}^{1,1}$ data. Two are expected, and both are fulfilled: (1) As the acrylate becomes larger (MA to BA to DA), $k_{\mathrm{t}}^{1,1}$ decreases (Table 1) due 
to the monomer becoming more viscous ( $\eta$ values of Table 2). (ii) The addition of toluene changes $k_{\mathrm{t}}^{1,1}$ according to whether this solvent is more viscous or more fluid than monomer. MA is more fluid (Table 2), meaning that $k_{\mathrm{t}}^{1,1}$ is larger in bulk (Table 1), while BA is more viscous (Table 2), resulting in $k_{\mathrm{t}}^{1,1}$ being larger in toluene solution (Table 1). The latter effect would be even starker in DA, a highly viscous monomer. All of these trends are made visual in Figure 4 (compare the $k_{\mathrm{t}}^{i, i}$ values for $i=1$ ).

INSERT Figure 4

The above trends may be put on a quantitative footing as follows. As already explained in the Introduction, Equations (2) and (3) predict that $k_{\mathrm{t}}^{1,1} r_{1} \eta$ should be relatively constant with variation of monomer and solvent, where $r_{1}$ is hydrodynamic radius of monomer. ${ }^{[29]}$ Crude estimates of relative $r_{1}$ values were obtained using $r_{1} \sim\left[n_{\mathrm{c}}(\mathrm{M})+n_{\mathrm{c}}(\mathrm{I})\right]^{0.5}$, where $n_{\mathrm{c}}(\mathrm{M})$ is the number of carbon atoms of the monomer and $n_{\mathrm{c}}(\mathrm{I})$ is the average number of non-hydrogen atoms per primary radical from MMMP (noting that the two initiating fragments of MMMP have similar sizes). This takes into account that a so-called monomeric free radical actually includes also an initiator fragment. The resulting estimates of size ratios are $r_{1}(\mathrm{MA}) / r_{1}(\mathrm{BA})=0.90$ and $r_{1}(\mathrm{MA}) / r_{1}(\mathrm{DA})=0.74$. Another estimated parameter value was $\eta$ for BA in toluene, which was assumed to be similar to $\eta$ for the MA mixture. The justification here is that toluene is the dominant component in both mixtures and BA is not too different to MA (cf. DA, which clearly does have a major effect on the solution viscosity, not just because of its size, but also because the constant concentration of 1.5 M translates into a lesser toluene amount).

INSERT Figure 5

Results for $k_{\mathrm{t}}^{1,1}$ and $k_{\mathrm{t}}^{1,1} r_{1} \eta$ are plotted in Figure 5. For ease of comparison all values have been reduced by the appropriate BA value. Specifically, the plot is of $k_{\mathrm{t}}^{1,1}(\mathrm{bulk}) / k_{\mathrm{t}}^{1,1}\left(\mathrm{BA}\right.$, bulk), $k_{\mathrm{t}}^{1,1}$ (solution) $/ k_{\mathrm{t}}^{1,1}\left(\mathrm{BA}\right.$, solution) $\quad$ and $\quad\left(k_{\mathrm{t}}^{1,1} r_{1} \eta\right) /\left[k_{\mathrm{t}}^{1,1} r_{1} \eta(\mathrm{BA}\right.$, bulk) $]$. 
Presentation this way makes it easy to see that whereas $k_{\mathrm{t}}^{1,1}$ values differ by up to a factor of 6, $k_{\mathrm{t}}^{1,1} r_{1} \eta$ values differ by less than $20 \%$, where most of this standardization comes from taking $\eta$ variation into account. This extends the remarkable finding of ref. ${ }^{[29]}$ and adds further weight to the notion that for acrylates and methacrylates, the variations of $k_{\mathrm{t}}^{1,1}$ due to monomer, solvent and temperature may largely be explained via very simple principles. Given this success it seems justified to recommend taking $E_{\mathrm{a}}\left(k_{\mathrm{t}}^{1,1}\right)=E_{\mathrm{a}}\left(\eta^{-1}\right)$ for (meth)acrylate systems where the former quantity has not been directly measured. It is for this reason that the latter values are made available in Table 2. The most obvious class of exceptions to the rules given here are highly hindered monomers, for example dibutyl itaconate. ${ }^{[19]}$ These have unusually low $k_{\mathrm{t}}{ }^{1,1}$ and unusually high $E_{\mathrm{a}}\left(k_{\mathrm{t}}{ }^{1,1}\right),{ }^{[19]}$ both of which are unlikely to be fully explained by simple viscosity and monomer-size variations. Rather, it may be necessary to invoke notions of shielding and of hindrance of segmental mobility in order to explain the data from such systems.

A propos shielding, inspection of Figure 5 reveals $k_{\mathrm{t}}^{1,1} r_{1} \eta$ for the two MA experiments is an average of $5 \%$ higher than the average BA value, while the DA value is $15 \%$ lower than for BA. It is tempting to suggest that these minor differences may be due to shielding of the radical center by the pendant group. In other words, long dodecyl groups are capable of blocking a radical from approach of another radical. In terms of Equation (2), one might say that the capture radius, $R_{\mathrm{c}}$, is reduced: the presence of potentially shielding groups means that two radicals must be closer in order to guarantee termination. While this paradoxical idea that a larger monomer has a smaller capture radius - is interesting and is consistent with the data, it is perhaps an over-interpretation, because the differences in reduced $k_{\mathrm{t}}^{1,1} r_{1} \eta$ values (20 $\%)$ are less than the error in these values, estimated to be at least $50 \%$ when the uncertainty in $k_{\mathrm{p}}$ is also taken into account.

Finally, as a summary of this Discussion we draw attention to Figure 4, which presents the measured composite-model variations of $k_{\mathrm{t}}^{i, i}$ for the 5 acrylate systems to have been 
studied so far by SP PLP EPR. All 5 variations are parallel to within experimental error, and for this reason it seems justified to speak of family-type behavior.

\section{Conclusion}

There are two themes we would like to touch on in conclusion. The first is as follows. Of the four composite-model parameters, $k_{\mathrm{t}}^{1,1}$ is arguably the most vital, because it sets the absolute value of $k_{\mathrm{t}}^{i, i}$ (see Figure 4), and thus it is the most important in determining the magnitude of the overall rate of termination. At the same time, it has been seen that in many ways $k_{\mathrm{t}}^{1,1}$ is the simplest parameter to understand for (meth)acrylate systems. Further, we have demonstrated that for such systems this understanding may easily be used to predict the value of $k_{\mathrm{t}}^{1,1}$, which varies by much more than $\alpha_{\mathrm{s}}, \alpha_{\mathrm{l}}$ and $i_{\mathrm{c}}$ from monomer to monomer (again, see Figure 4 ). Furthermore, once $k_{\mathrm{t}}^{1,1}$ is predicted accurately, there are reasonable rules for estimating the values of the other parameters. The ones from this work are that $\alpha_{\mathrm{s}}=0.79, \alpha_{\mathrm{l}}=0.21$ and $i_{\mathrm{c}} \approx$ 30 for acrylate SPRs (see the family-type behavior illustrated by Figure 4). Thus it is possible to predict $k_{\mathrm{t}}^{i, i}$ (and hence overall rate of termination), with the success of this venture most crucially depending on the accuracy of $k_{\mathrm{t}}^{1,1}$.

Our second concluding point is simply to draw attention to the astonishing progress in understanding of acrylate kinetics that has taken place over the last decade. Lovell et al. may be said to have put the key in the lock with their 1998 paper proving the occurrence of chain transfer to polymer in $\mathrm{BA}^{[52]}$ This awakened workers to the reality of this reaction in acrylate systems, and rapidly led to an appreciation of how this simple reaction affects the measurement of all fundamental rate coefficients. As a result one may now survey a landscape in which much is known about acrylate kinetics $\left.{ }^{[1,} 13\right]$ where previously only mystery abounded. This paper adds further details to this landscape, notably a clearer picture of acrylate termination kinetics. Although the present work did not involve mid-chain radicals 
explicitly, that is exactly the point: only once there is a foundation of precise knowledge about secondary-radical kinetics may one progress to understanding MCR kinetics at higher temperatures.

Overall it must be said that the comprehensive picture of acrylate kinetics that is taking shape is a pleasing one, and more fool those who dismiss either the importance of this picture or the beauty in it.

Supporting Information containing measured values of $v$ (kinematic viscosity), $\rho$ (mixture density) and $\eta$ (dynamic viscosity) is available free of charge via the internet

Acknowledgements: J.B. is grateful to the Fonds der Chemischen Industrie for financial support. The authors acknowledge Prof. F. Meyer (Institute for Inorganic Chemistry, University of Göttingen) for providing the opportunity to use the EPR spectrometer in his laboratory. G.T.R. thanks the University of Canterbury for provision of study leave, during which this project was carried out. 
Table 1. Values of the composite-model termination parameters $\alpha_{\mathrm{s}}$ (short-chain exponent), $\alpha_{\mathrm{I}}$ (long-chain exponent), $i_{\mathrm{c}}$ (crossover chain length) and $k_{\mathrm{t}}^{1,1}$ (termination rate coefficient for monomeric radicals) for methyl acrylate (MA), n-butyl acrylate (BA) and dodecyl acrylate (DA). Values in bold are measurements of this work, ${ }^{a}$ others are as indicated from the literature.

\begin{tabular}{|c|c|c|c|c|}
\hline Parameter & MA & $\mathbf{B A}$ & $\mathbf{D A}^{\mathbf{b})}$ & $\begin{array}{c}\text { Method; experimental } \\
\text { conditions }^{\text {c) }}\end{array}$ \\
\hline \multirow{4}{*}{$\alpha_{\mathrm{s}}$} & $0.78^{[48]}$ & $1.04^{[22]}$ & $1.15 \pm 0.05^{[35]}$ & $\begin{array}{c}\text { RAFT CLDT; bulk, } 50^{\circ} \mathrm{C} \\
\text { (MA) or } 80^{\circ} \mathrm{C}\end{array}$ \\
\hline & $0.78 \pm 0.15^{[34]}$ & $1.25^{[22]}$ & $1.12 \pm 0.15^{[34]}$ & $\begin{array}{l}\text { SP PLP RAFT; bulk, } \\
80{ }^{\circ} \mathrm{C} / 1 \text { bar (BA) or } \\
\quad 60{ }^{\circ} \mathrm{C} / 1000 \text { bar }\end{array}$ \\
\hline & $0.80 \pm 0.15$ & $0.71 \pm 0.15$ & - & SP PLP EPR; bulk, $-40^{\circ} \mathrm{C}$ \\
\hline & $0.74 \pm 0.15$ & $0.85 \pm 0.09^{[13]}$ & $\begin{array}{c}0.87 \pm 0.15 \\
(0.78 \pm 0.15)\end{array}$ & $\begin{array}{l}\text { SP PLP EPR; } 1.5 \mathrm{M} \text { in } \\
\text { toluene, }-40{ }^{\circ} \mathrm{C}\end{array}$ \\
\hline \multirow{4}{*}{$\alpha_{1}$} & $0.15^{[48]}$ & $0.20^{[22]}$ & $0.22 \pm 0.05^{[35]}$ & $\begin{array}{c}\text { RAFT CLDT; bulk, } 50^{\circ} \mathrm{C} \\
\text { (MA) or } 80{ }^{\circ} \mathrm{C}\end{array}$ \\
\hline & $0.26 \pm 0.06^{[34]}$ & $0.22^{[22]}$ & $0.20 \pm 0.04^{[34]}$ & $\begin{array}{l}\text { SP PLP RAFT; bulk, } \\
80{ }^{\circ} \mathrm{C} / 1 \text { bar (BA) or } \\
\quad 60^{\circ} \mathrm{C} / 1000 \text { bar }\end{array}$ \\
\hline & $0.25 \pm 0.07$ & $0.26 \pm 0.07$ & - & SP PLP EPR; bulk, $-40{ }^{\circ} \mathrm{C}$ \\
\hline & $0.15 \pm 0.07$ & $0.22 \pm 0.07^{[13]}$ & $0.19 \pm 0.07$ & $\begin{array}{l}\text { SP PLP EPR; } 1.5 \mathrm{M} \text { in } \\
\text { toluene, }-40^{\circ} \mathrm{C}\end{array}$ \\
\hline
\end{tabular}




\begin{tabular}{|c|c|c|c|c|}
\hline \multirow{5}{*}{$i_{\mathrm{c}}$} & $20^{[48]}$ & $30^{[22]}$ & $20^{[35]}$ & $\begin{array}{c}\text { RAFT CLDT; bulk, } 50^{\circ} \mathrm{C} \\
\text { (MA) or } 80{ }^{\circ} \mathrm{C}\end{array}$ \\
\hline & $30^{[34]}$ & $30^{[22]}$ & $20^{[34]}$ & $\begin{array}{l}\text { SP PLP RAFT; bulk, } \\
80{ }^{\circ} \mathrm{C} / 1 \text { bar (BA) or } \\
\quad 60{ }^{\circ} \mathrm{C} / 1000 \text { bar }\end{array}$ \\
\hline & $35 \pm 10$ & $65 \pm 20$ & - & SP PLP EPR; bulk, $-40^{\circ} \mathrm{C}$ \\
\hline & $25 \pm 10$ & $30 \pm 5^{[13]}$ & $\begin{array}{c}50 \pm 25 \\
(100 \pm 25)\end{array}$ & $\begin{array}{l}\text { SP PLP EPR; } 1.5 \mathrm{M} \text { in } \\
\text { toluene, }-40{ }^{\circ} \mathrm{C}\end{array}$ \\
\hline & $3 \times 10^{8[48]}$ & $3.5 \times 10^{8[22]}$ & $5.6 \times 10^{7[35]}$ & RAFT CLDT; bulk ${ }^{\mathrm{d})}$ \\
\hline \multirow{3}{*}{$k_{\mathrm{t}}^{1,1} / \mathrm{L} \cdot \mathrm{mol}^{-1} \cdot \mathrm{s}^{-1}$} & $6.6 \times 10^{8[34]}$ & $4.4 \times 10^{8[22]}$ & $6.3 \times 10^{7[34]}$ & SP PLP RAFT; bulk ${ }^{\mathrm{d})}$ \\
\hline & $3.0 \times 10^{8}$ & $9.5 \times 10^{7}$ & - & SP PLP EPR; bulk \\
\hline & $2.1 \times 10^{8}$ & $1.9 \times 10^{8[13]}$ & $\begin{array}{c}3.4 \times 10^{7} \\
\left(5.0 \times 10^{7}\right)\end{array}$ & $\begin{array}{l}\text { SP PLP EPR; } 1.5 \mathrm{M} \text { in } \\
\text { toluene }\end{array}$ \\
\hline
\end{tabular}

a) Average values from up to five individual experiments under identical experimental conditions; ${ }^{\mathrm{b})}$ Values not in brackets are from data analysis using $k_{\mathrm{p}}$ estimated for polymerization in toluene, ${ }^{[42,43]}$ values in brackets are from using bulk $k_{\mathrm{p}}$ (see text). Note that $k_{\mathrm{p}}$ does not influence the value of $\alpha_{\mathrm{l}}$ (see Equation (4)); ${ }^{\text {c) }} 1$ bar unless otherwise stated; ${ }^{\mathrm{d}}$ literature values adjusted to $-40{ }^{\circ} \mathrm{C}$ and 1 bar using $E_{\mathrm{a}}\left(k_{\mathrm{t}}{ }^{1,1}\right)=E_{\mathrm{a}}\left(\eta^{-1}\right)$ from Table 2 and $\Delta V^{\ddagger}\left(k_{\mathrm{t}}\right)=-2.0 \times 10^{1} \mathrm{~cm}^{3} \cdot \mathrm{mol}^{-1}$ 
Table 2. Values of activation energy for inverse viscosity, $E_{\mathrm{a}}\left(\eta^{-1}\right)$, and of viscosity at $-40{ }^{\circ} \mathrm{C}$ for methyl acrylate (MA), n-butyl acrylate (BA) and dodecyl acrylate (DA).

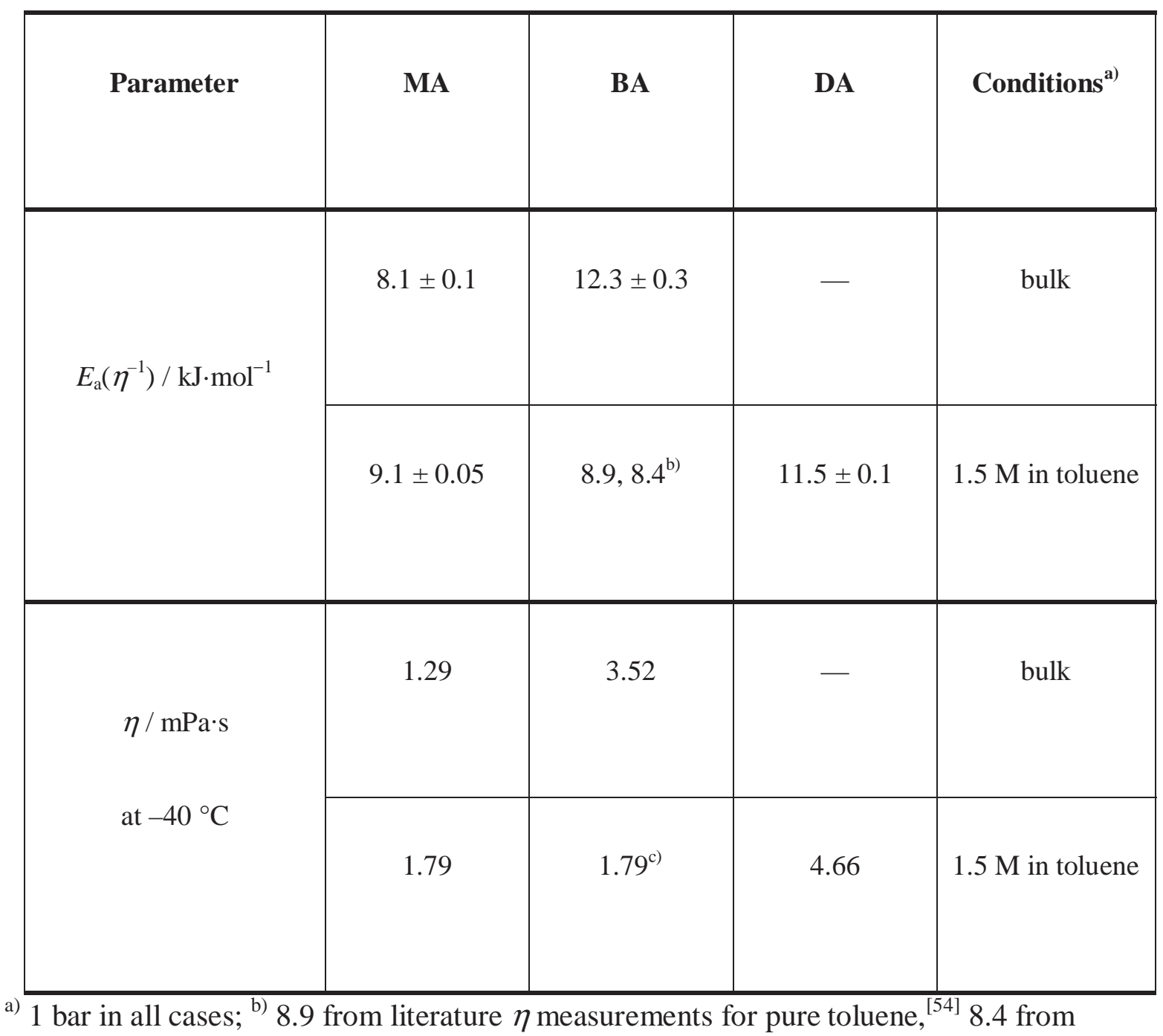

literature $k_{\mathrm{t}}^{1,1}$ measurements. ${ }^{[13]}$ Note that this activation energy was not required in this work;

${ }^{c}$ Not measured, therefore assumed to be the same as for MA in toluene. 


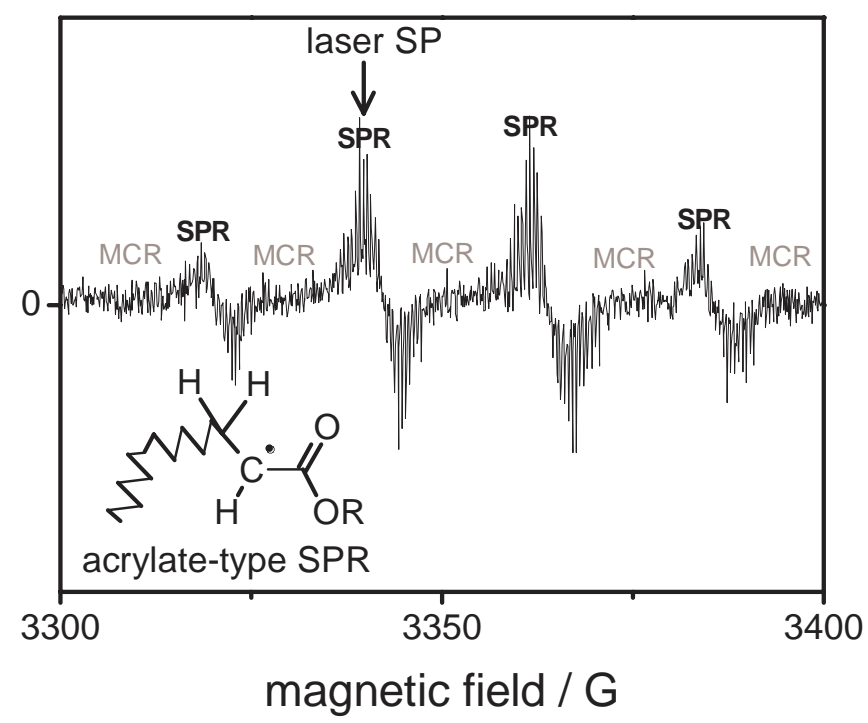

Figure 1. Full EPR spectrum recorded during PLP of MA $\left(\mathrm{R}=\right.$ methyl) in toluene at $-40{ }^{\circ} \mathrm{C}$. Essentially identical spectra were observed for polymerization of BA ( $\mathrm{R}=n$-butyl) and DA $(\mathrm{R}=$ dodecyl) under the same conditions. 'SPR' refers to lines from secondary propagating radicals, while the positions of mid-chain-radical lines that occur at higher temperatures are indicated by the grey letters 'MCR'. The arrow indicates the constant field position that was used in the subsequent SP PLP EPR experiment for monitoring $c_{\mathrm{R}}$ as a function of time (see text). 


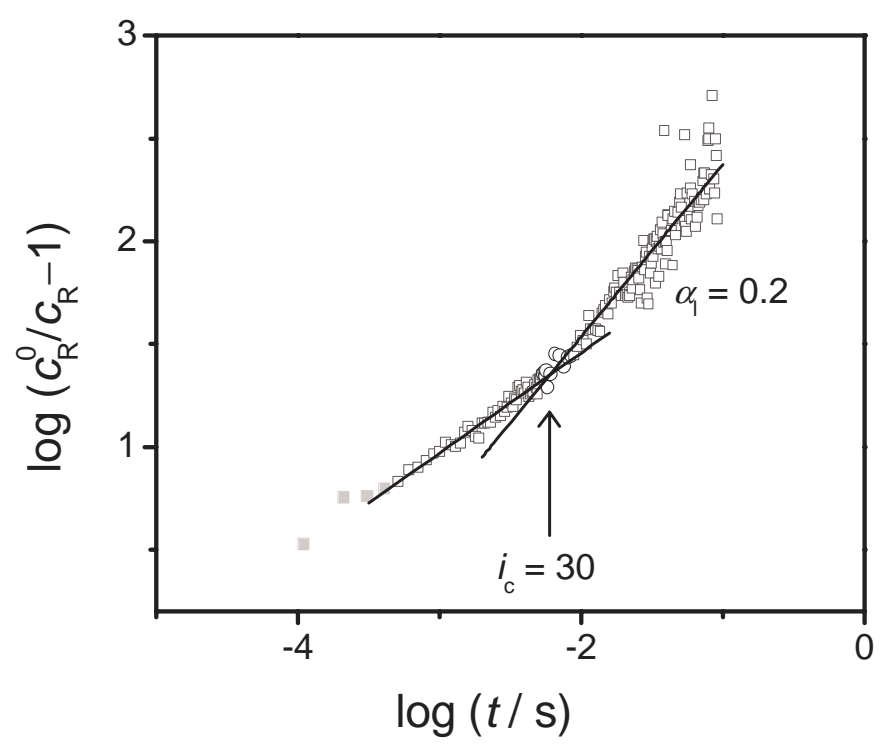

Figure 2. Fits of straight lines to the experimental $c_{\mathrm{R}}(t)$ data from an SP PLP EPR experiment on MA at $-40{ }^{\circ} \mathrm{C}$. Empty squares: points used for linear fits; empty circles: points in the crossover region and therefore not used for either linear fit; filled squares: points at very early time that require Equation (5) in order to be properly fitted and therefore not used for linear fitting. The slope of the linear fit to the long-time data is used to obtain $\alpha_{1}$ via Equation (4), while the crossover chain length, $i_{\mathrm{c}}$, is obtained from the intercept of the two linear fits. 


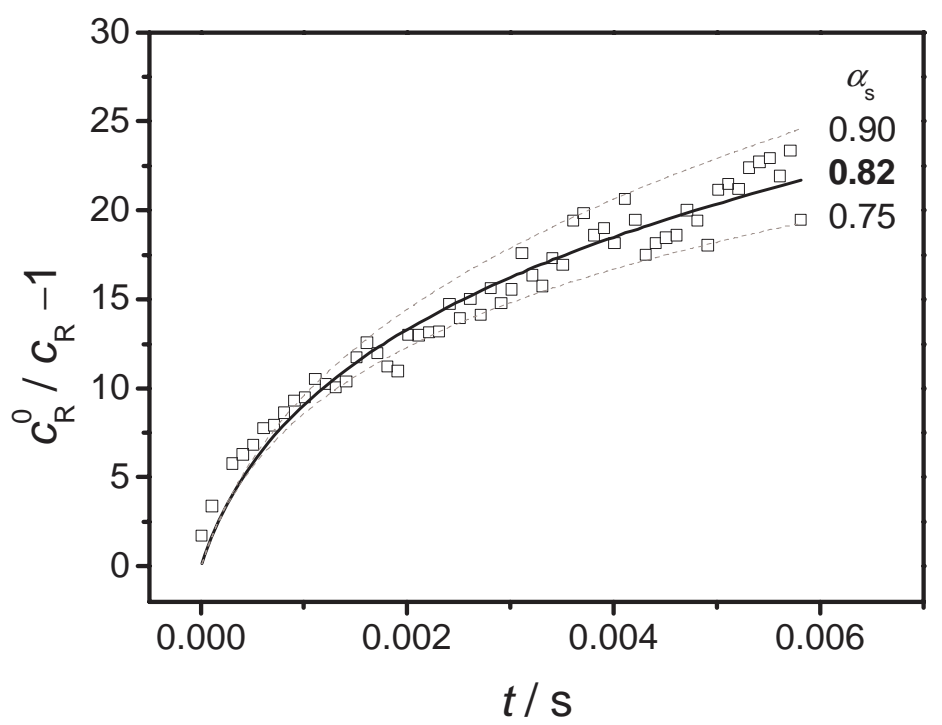

Figure 3. Fitting of Equation (5) to early-time data from SP PLP EPR of MA (1.5 M in toluene) at $-40{ }^{\circ} \mathrm{C}$. The solid line represents the best fit to the data, yielding $\alpha_{\mathrm{s}}=0.82$ and $k_{\mathrm{t}}^{1,1}$ $=1.8 \times 10^{8} \mathrm{~L} \cdot \mathrm{mol}^{-1} \cdot \mathrm{s}^{-1}$ (note that these values do not appear directly in Table 1 because it contains averages over all experiments, including this one). The dashed lines are evaluations of Equation (5) using $\alpha_{\mathrm{s}}=0.75$ and 0.90 in order to illustrate the precision of the fitted $\alpha_{\mathrm{s}}$ value. 


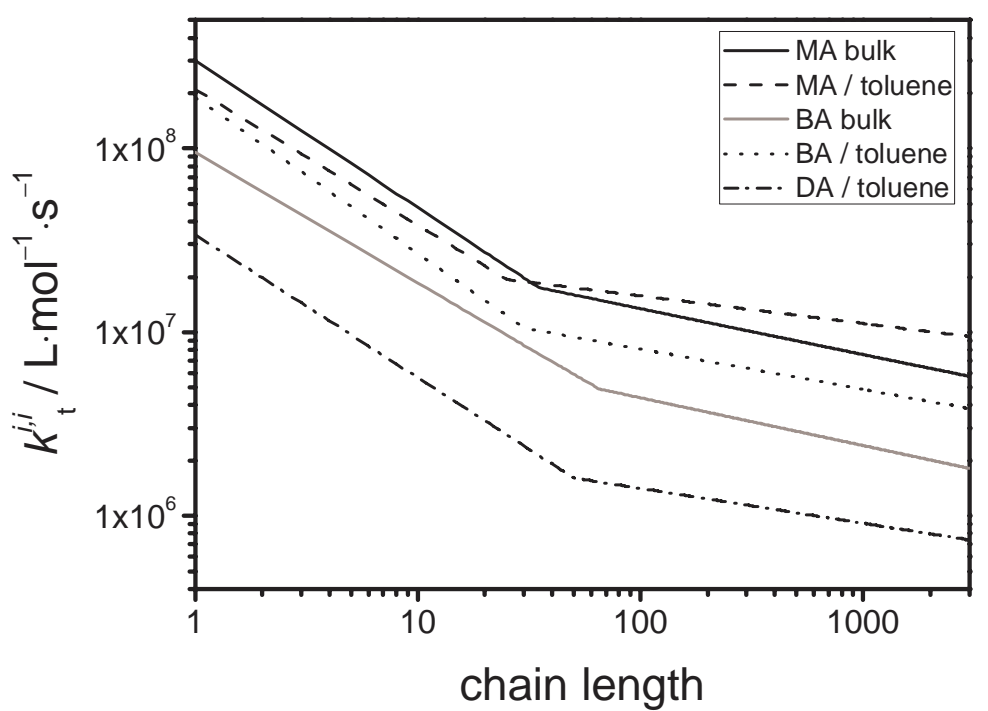

Figure 4. Measured composite-model (Equation (1)) variations of homotermination rate coefficients, $k_{\mathrm{t}}^{i, i}$, as a function of chain length, $i$, for the five systems of this work, as indicated. This plot is effectively a visual presentation of the SP PLP EPR parameter values of Table 1. 


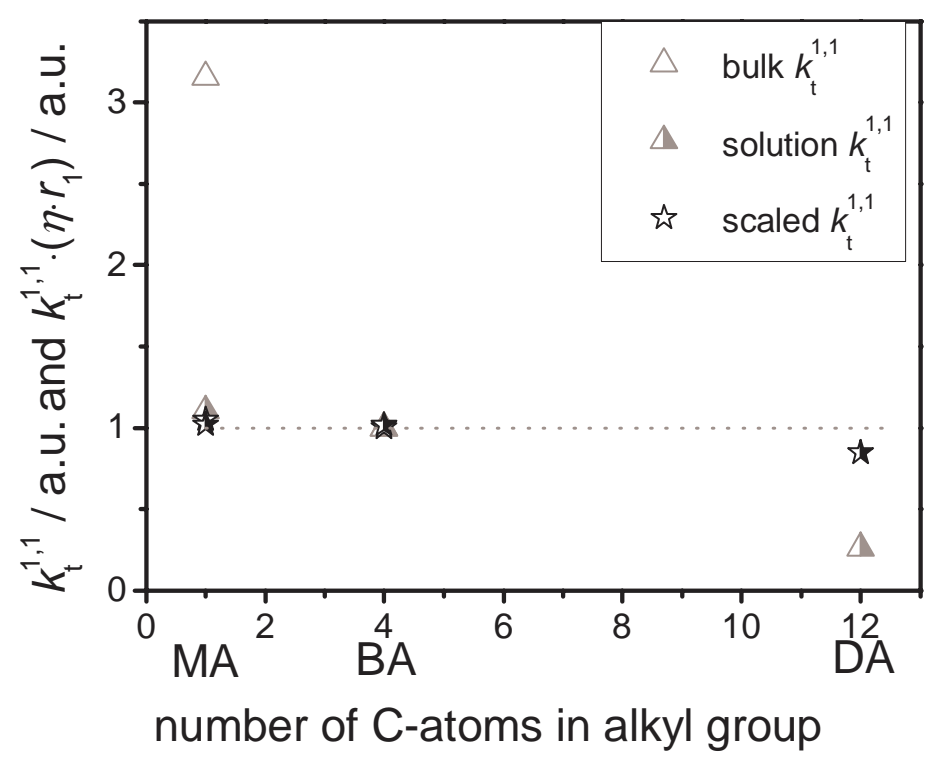

Figure 5. Analysis of experimental values from this work for monomeric termination rate coefficients, $k_{\mathrm{t}}^{1,1}$, of acrylates. Open triangles: bulk values divided by bulk BA value; halffilled triangles: toluene solution values divided by solution BA value; stars: scaled values $k_{\mathrm{t}}^{1,1} r_{1} \eta$ divided by bulk BA scaled value. The scaled values cluster around $1-$ shown as a dotted horizontal line - whereas the unscaled values show trends associated with variation of solution viscosity and monomer size (see text). 


\section{References}

[1] T. Junkers, C. Barner-Kowollik, J. Polym. Sci. Polym. Chem. 2008, 46, 7585.

[2] G. E. Scott, E. Senogles, Journal of Macromolecular Science-Chemistry 1970, A 4, 1105.

[3] G. E. Scott, E. Senogles, J. Macromol. Sci. Rev. Macromol. Chem. Phys. 1973, C 9, 49.

[4] G. E. Scott, E. Senogles, Journal of Macromolecular Science-Chemistry 1974, A 8, 753.

[5] S. Beuermann, D. A. Paquet, J. H. McMinn, R. A. Hutchinson, Macromolecules 1996, $29,4206$.

[6] J. M. Asua, S. Beuermann, M. Buback, P. Castignolles, B. Charleux, R. G. Gilbert, R. A. Hutchinson, J. R. Leiza, A. N. Nikitin, J. P. Vairon, A. M. van Herk, Macromol. Chem. Phys. 2004, 205, 2151.

[7] R. X. E. Willemse, A. M. van Herk, E. Panchenko, T. Junkers, M. Buback, Macromolecules 2005, $38,5098$.

[8] A. N. Nikitin, R. A. Hutchinson, Macromolecules 2005, 38, 1581.

[9] A. Kajiwara, ACS Symp. Ser. 2006, 944, 111.

[10] A. Kajiwara, A. K. Nanda, K. Matyjaszewski, Macromolecules 2004, 37, 1378.

[11] A. Kajiwara, M. Kamachi, ASC Symposium Ser. 2003, 854, 86.

[12] J. Barth, M. Buback, P. Hesse, T. Sergeeva, Macromol. Rapid Commun. 2009, 30, 1969.

[13] J. Barth, M. Buback, P. Hesse, T. Sergeeva, Macromolecules 2010, 43, 4023.

[14] C. Barner-Kowollik, F. Gunzler, T. Junkers, Macromolecules 2008, 41, 8971.

[15] K. F. O'Driscoll, H. K. Mahabadi, J. Polym. Sci. Polym. Chem. 1976, 14, 869.

[16] A. N. Nikitin, R. A. Hutchinson, M. Buback, P. Hesse, Macromolecules 2007, 40, 8631.

[17] C. Barner-Kowollik, M. Buback, M. Egorov, T. Fukuda, A. Goto, O. F. Olaj, G. T. Russell, P. Vana, B. Yamada, P. B. Zetterlund, Prog. Polym. Sci. 2005, 30, 605.

[18] C. Barner-Kowollik, G. T. Russell, Prog. Polym. Sci. 2009, 34, 1211.

[19] M. Buback, M. Egorov, T. Junkers, E. Panchenko, Macromol. Chem. Phys. 2005, 206, 333.

[20] O. F. Olaj, P. Vana, A. Kornherr, G. Zifferer, Macromol. Chem. Phys. 1999, 200, 2031.

[21] M. Buback, T. Junkers, Macromol. Chem. Phys. 2006, 207, 1640.

[22] T. Junkers, A. Theis, M. Buback, T. P. Davis, M. H. Stenzel, P. Vana, C. Barner-Kowollik, Macromolecules 2005, $38,9497$.

[23] G. B. Smith, G. T. Russell, J. P. A. Heuts, Macromol. Theor. Simul. 2003, 12, 299.

[24] B. Friedman, B. Oshaughnessy, Macromolecules 1993, 26, 5726.

[25] O. F. Olaj, P. Vana, Macromol. Rapid Commun. 1998, 19, 533.

[26] O. F. Olaj, P. Vana, Macromol. Rapid Commun. 1998, 19, 433.

[27] H. Fischer, H. Paul, Accounts Chem Res 1987, 20, 200.

[28] G. T. Russell, R. G. Gilbert, D. H. Napper, Macromolecules 1993, $26,3538$.

[29] J. Barth, M. Buback, Macromol. React. Eng. 2010, 4, 288.

[30] J. Barth, M. Buback, Macromol. Rapid Comm. 2009, 30, 1805.

[31] M. C. Griffiths, J. Strauch, M. J. Monteiro, R. G. Gilbert, Macromolecules 1998, 31, 7835.

[32] M. C. Piton, R. G. Gilbert, B. E. Chapman, P. W. Kuchel, Macromolecules 1993, 26, 4472.

[33] A. Theis, A. Feldermann, N. Charton, T. P. Davis, M. H. Stenzel, C. Barner-Kowollik, Polymer 2005, 46, 6797.

[34] M. Buback, P. Hesse, T. Junkers, T. Theis, P. Vana, Aust. J. Chem. 2007, 60, 779.

[35] A. Theis, A. Feldermann, N. Charton, M. H. Stenzel, T. P. Davis, C. Barner-Kowollik, Macromolecules 2005, 38, 2595.

[36] J. Barth, M. Buback, P. Hesse, T. Sergeeva, Macromolecules 2009, 42, 481.

[37] M. Buback, E. Muller, G. T. Russell, J. Phys. Chem. A 2006, 110, 3222.

[38] M. Buback, M. Egorov, T. Junkers, E. Panchenko, Macromol. Rapid Commun. 2004, 25, 1004.

[39] G. B. Smith, G. T. Russell, Z. Phys. Chem. (Munich) 2005, 219, 295.

[40] M. Buback, C. H. Kurz, C. Schmaltz, Macromol. Chem. Phys. 1998, 199, 1721.

[41] S. Beuermann, M. Buback, C. Schmaltz, Macromolecules 1998, 31, 8069.

[42] M. Buback, Macromol. Symp. 2009, 275-276, 90.

[43] L. Couvreur, G. Piteau, P. Castignolles, M. Tonge, B. Coutin, B. Charleux, J. P. Vairon, Macromol. Symp. 2001, 174, 197.

[44] S. Beuermann, M. Buback, T. P. Davis, R. G. Gilbert, R. A. Hutchinson, A. Kajiwara, B. Klumperman, G. T. Russell, Macromol. Chem. Phys. 2000, 201, 1355.

[45] G. Johnston-Hall, A. Theis, M. J. Monteiro, T. P. Davis, M. H. Stenzel, C. Barner-Kowollik, Macromol. Chem. Phys. 2005, 206, 2047.

[46] P. J. Flory, Principles of Polymer Chemistry, New York, Ithaca, 1953.

[47] J. Strauch, J. McDonald, B. E. Chapman, P. W. Kuchel, B. S. Hawkett, G. E. Roberts, M. P. Tonge, R. G. Gilbert, J. Polym. Sci. Polym. Chem. 2003, 41, 2491.

[48] G. Johnston-Hall, M. J. Monteiro, J. Polym. Sci. Polym. Chem. 2008, 46, 3155.

[49] M. G. Frohlich, P. Vana, G. Zifferer, J. Chem. Phys. 2007, 127.

[50] M. G. Frohlich, P. Vana, G. Zifferer, Macromol. Theor. Simul. 2007, 16, 610.

[51] H. A. Schneider, Polymer 2005, 46, 2230.

[52] N. M. Ahmad, F. Heatley, P. A. Lovell, Macromolecules 1998, 31, 2822

[53] S. Beuermann, M. Buback, Prog. Polym. Sci. 2002, 27, 191.

[54] K. R. Harris, J Chem Eng Data 2000, 45, 893. 
Copyright WILEY-VCH Verlag GmbH \& Co. KGaA, 69469 Weinheim, Germany, 2011.

Supporting Information for Macromol. Chem. Phys. 2011, 212, xxx.

\section{Chain-Length-Dependent Termination in Radical Polymerization of Acrylates}

Johannes Barth, Michael Buback, Gregory T. Russell, ${ }^{*}$ Sebastian Smolne

M. Buback, J. Barth, S. Smolne

Institute for Physical Chemistry, University of Göttingen, Tammannstraße 6, D-37077

Göttingen, Germany

Fax: +49 551 393144; E-mail: mbuback@gwdg.de

G. T. Russell

Department of Chemistry, University of Canterbury, Private Bag 4800, Christchurch, New Zealand

Fax: +64 3 3642110; E-mail: greg.russell@canterbury.ac.nz 
Table S1. Measurements of $v$ (kinematic viscosity), $\rho$ (mixture density) and $\eta$ (dynamic viscosity) for all methyl acrylate (MA), $n$-butyl acrylate (BA) and dodecyl acrylate (DA) as a function of temperature (top row of each section; in $\mathrm{K}$ ). Each value is the average from three replicate experiments.

\begin{tabular}{|c|c|c|c|c|c|c|c|c|}
\hline MA (bulk) & 278.15 & 283.15 & 288.15 & 293.15 & 303.15 & 313.15 & 323.15 & 333.15 \\
\hline$v / \mathrm{mm}^{2} \cdot \mathrm{s}^{-1}$ & 0.733 & 0.698 & 0.658 & 0.617 & 0.561 & 0.519 & 0.464 & 0.443 \\
\hline$\rho / \mathrm{g} \cdot \mathrm{mL}$ & 0.887 & 0.883 & 0.879 & 0.875 & 0.867 & 0.858 & 0.850 & 0.842 \\
\hline$\eta / \mathrm{mPa} \cdot \mathrm{s}$ & 0.650 & 0.616 & 0.579 & 0.540 & 0.487 & 0.446 & 0.394 & 0.373 \\
\hline BA (bulk) & 278.15 & 283.15 & 288.15 & 303.15 & 323.15 & & & \\
\hline$v / \mathrm{mm}^{2} \cdot \mathrm{s}^{-1}$ & 1.44 & 1.33 & 1.12 & 0.91 & 0.72 & & & \\
\hline$\rho / \mathrm{g} \cdot \mathrm{mL}$ & 0.887 & 0.883 & 0.879 & 0.867 & 0.850 & & & \\
\hline$\eta / \mathrm{mPa} \cdot \mathrm{s}$ & 1.28 & 1.18 & 0.99 & 0.79 & 0.61 & & & \\
\hline 1.5 M MA in toluene & 278.15 & 283.15 & 288.15 & 303.15 & 323.15 & & & \\
\hline$v / \mathrm{mm}^{2} \cdot \mathrm{s}^{-1}$ & 0.845 & 0.794 & 0.745 & 0.636 & 0.520 & & & \\
\hline$\rho / \mathrm{g} \cdot \mathrm{mL}$ & 0.970 & 0.965 & 0.953 & 0.929 & 0.908 & & & \\
\hline$\eta / \mathrm{mPa} \cdot \mathrm{s}$ & 0.820 & 0.766 & 0.711 & 0.591 & 0.472 & & & \\
\hline 1.5 M DA in toluene & 278.15 & 283.15 & 288.15 & 303.15 & 323.15 & & & \\
\hline$v / \mathrm{mm}^{2} \cdot \mathrm{s}^{-1}$ & 1.96 & 1.82 & 1.64 & 1.31 & 1.05 & & & \\
\hline$\rho / \mathrm{g} \cdot \mathrm{mL}$ & 0.9136 & 0.9089 & 0.8976 & 0.875 & 0.8552 & & & \\
\hline$\eta / \mathrm{mPa} \cdot \mathrm{s}$ & 1.788 & 1.650 & 1.473 & 1.150 & 0.899 & & & \\
\hline
\end{tabular}


Figure S1. Arrhenius plot of $\eta$ versus $T$ for the results of Table S1. The numbers at the righthand side are the absolute value of the activation energy for each data set. The vertical arrow marks the temperature of the kinetic measurements of the main text.

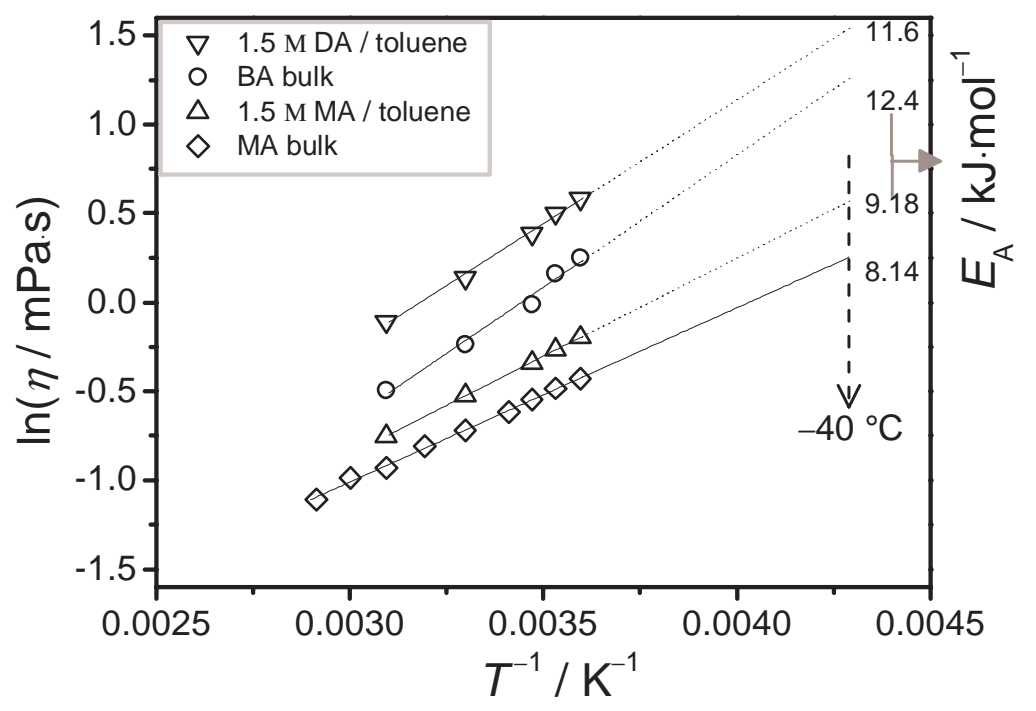

